\title{
RECENT DEVELOPMENTS IN THE THEORY OF STABILIZATION POLICY
}

John B. Taylor

During the past decade the theoretical framework underlying macroeconomic stabilization analysis has undergone a number of significant developments. Theories designed to explain the crucial linkage between aggregate demand policy and real economic variables have been revised following the research on the "new microfoundations" of employment and inflation. Critical expectations effects of stabilization policy have been incorporated into the theoretical framework through the use of rational expectations. Optimal control techniques have become sophisticated enough to be used on large nonlinear econometric models, and more recently have been adapted for use in models with endogenous expectations. Supply considerations have been recognized as having important policy implications and, when necessary, have been incorporated into policy analyses. Theories underlying the choice between rules and discretionary policy have been altered and refined. These developments are likely to play an important role in the practical evaluation of economic policy in the years ahead.

This paper reviews these developments in the theory of stabi1ization policy and outlines some of their implications for macroeconomic policy evaluation. The first section reviews the theories which have

John B. Taylor is Professor of Economics, Columbia University. The author wishes to thank Robert Barro, Jerry Green, Dale Henderson, and Laurence Meyer for helpfu] comments on an earlier draft, and the National Science Foundation for financial support. 
been developed to explain the effect of policy variables on the real economy. As there is still little consensus here, a number of alternative representative models are presented and compared. The second section examines the implications of these different thearies for the problem of reducing the rate of inflation, which is likely to be one of the more important policy issues in the years ahead. The third section discusses a number of issues which have arisen in recent policy analyses and which are closely related to the changes in the theoretical framework: The Lucas critique of traditional poljcy evaluation procedures, the applicability of optimal control, the choice of rules versus discretion, and the applicability of the new equitibrium approach to stabilization policy.

With few exceptions this review focuses on theoretical research on domestic stabilization policies. International considerations and empirical results are reviewed in other papers prepared for this conference. Some of the topics reviewed here have recently been the subject of a large number of survey and expositional works. The variety of survey papers by Barro (1979), Buiter (1979), Fishcer (1979), McCal 7 um (1979), Phelps (1979), Prescott (1977), Santomero and Seater (1978), and Shitler (1978) and the books by the Ball committee (1978), and Sargent (1979) provide further detail and alternative perspectives on the topics reviewed here.

Expectations play a predominant role in any discussion of stabilization analysis. For the discussion that follows, the benchmark assumption wilt be that expectations are formed rationally. Variations from this benchmark - - due perhaps to the necessity of people gradually learning about whether the economy has undergone a structural change -- are 
considered in the course of the discussion along with variations in the model underlying the policy analysis.

THEORIES OF AGGREGATE DEMAND EFFECTS ON REAL OUTPUT AND EMPLOYMENT

In the idealized world of complete markets with perfect information about opportunities in a11 markets, changes in the money supply -or more generally, changes in aggregate demand -- do not affect real economic variables such as real GNP and employment. Apart from distribution effects, aggregate demand fluctuations are translated point-forpoint into price fluctuations. Money is neutral. Many of the theoretical developments in macroeconomics in the 1970 s have been concerned with explaining, in more detail and with more rigor than earlier theories, why this neutrality is not observed in the real world. A reasonably firm understanding of the mechanism generating this nonneutrality is certainly necessary for evaluating stabilization policy because aggregate demand management tools, such as money growth and government expenditure plans, are the primary instruments of stabilization policy."

\footnotetext{
The effects of government policies which impact directly on relative prices can be evaluated in principle using the standard a locative theories of microeconomics. Sone examples: a relative lowering of tax rates on capital would be expected to stimulate investment by raising the desired capital-labor ratio; a higher steady rate of inflation has allocation effects by acting as a tax on real money balances; and unemployment insurance can raise the equilibrium unemployment rate by driving a wedge into the work-leisure tradeoff. Apart from disagreement over the magnitude of the relevant elasticities for measuring these effects, there has been a general consensus among economists that such policies have real effects. However, because these policies are used for allocative or distributional purposes, they are not generally flexible enough to be considered seriously in stabi1 ization analysis. Nevertheless, their importance cannot be overlooked in analyzing macroeconomic trends. See Feldstein (1978) for a summary of such effects on unemployment.
} 
Recent theories of the observed link between aggregate demand and real variables can be grouped into two types - information-based theories in which the uncertainties about economy-wide disturbances are emphasized, and contract-based theories in which temporary rigidities in prices and wages are emphasized. At the risk of becoming too taxonomic, it will be useful to further classify each of these theories. Among the information-based theories it is important to distinguish between those in which the uncertainty is whether an observed economic change is local or economy-wide, and those in which the uncertainty is whether an economic change is temporary or permanent. Similarly, among the contract-based theories it is important to distinguish between those that emphasize relative price shifts due to asymetrical rigidities (for example, wages are rigid white prices are flexible), and those that emphasize the general persistence of all prices due to nonsynchronous price (or wage) setting relative to a prevailing trend in prices (or wages).

Uncertainty about Locał Versus Aggregate Economic Conditions

Perhaps the most significant finding of the research" on the "new microeconomics" is that imperfect information about economic conditions outside an individual's own market or industry can have profound implications for the behavior of inflation and employment. Suppose aggregate demand increases because of a higher rate of money growth. Then individual firms will find an increased demand for their products, and will respond by increasing their production (and perhaps running down

\footnotetext{
${ }^{2}$ See phelps et al (1970).
} 
their inventories of finished goods). But much of this higher real Jroduction may be due to the misperception on the part of each firm that the increased demand is a relative shift toward the product it sel1s. 3ecause there is always imperfect information about whether an increase in sales is a local phenomenon, this misperception and the consequent real output response is unavoidable. If, on the contrary, each firm knew that the increase in demand was common to all firms in the econory, and was due to the purely nominal increase in the money supply, then its sroduction response would be much smaller. If prices and wages were generally flexible, then firms would know that prices and wages should quickly rise to offset the increase in the money supply, and therefore that an increase in output would not be warranted. In the liniting case of perfectly flexible prices, good information about what is going on elsewhere in the economy enables firms to respond just as they would be predicted to do in the money-neutral world of general equilibrium theory. But even with perfectly flexible prices, imperfect information creates a non-neutrality in which firms respond to aggregate demand stimulus by increasing real output. The link between aggregate demand and real varim ables, according to this theory, depends in no essential way on price or wage rigidities. As long as there is imperfect information about the source of aggregate demand shifts, the correlation between aggregate demand and real output will exist. Of course, the possibility of a coincidence of perfectly flexible prices and wages with these we 11-known empirical correlations means that policy implications will be much different. Simple descriptions of this theory are found in Phelps et al. (1970) and Lucas (1973). The algebra of the Lucas presentation is 
convenient for our purposes and can be represented in terms of a simple quantity theory of aggregate demand.

$$
y+p=m+v
$$

combined with an "aggregate supply" equation

$$
y=\alpha(p-\hat{p})
$$

All variables are measured in logarithms and should be thought of as deviations from secular trends: $y$ is real GNP, $p$ is the aggregate price index, $m$ is the money supply, and $v$ is velocity. The $\hat{p}$ tem represents a forecast of the price level before the information about m and $v$ becomes avajlable. The difference between $p$ and $\hat{p}$ represents the average difference between each firm's observation of demand conditions during the period and its guess about economy-wide demand conditions. This difference represents the misperception or mistake discussed above which causes firms to increase their production. The sum of all firms' production responses is $y$. (It turns out that it is convenient algebraically to use prices to index demand conditions.)

Substituting from (1) into (2) and noting that from (2) that $\hat{y}=0$, we find ${ }^{3}$

$$
y=\alpha(m-\hat{n}+v-\hat{v}) .
$$

${ }^{3}$ We take $\hat{\mathrm{p}}$ to be a rational (unbiased) forecast of $\mathrm{p}$; hence $E(p-\hat{p})=0$. "Biased" forecasts are treated in section 1.2 below and arise because of information confusion about what is the actual model underlying policy or the structure of the economy. These "biased" forecasts have forms which resemble adaptive expectations, but unlike adaptive expectations are closely related to the structure of the model. 
Hence reai output responds positively to unanticipated money $m-\hat{m}$ and unanticipated velocity $v-\hat{v}$. This is the critical link between real variables and aggregate demand which the theory explains.

However, because only unanticipated changes in aggregate demand affect real output, the policy implications of this linkage theory are striking: if the monetary authorities change their policy instrument $m$ in a way which can be predicted by individuals in the economy, then in our notation $m=\hat{m}$ and the change in $m$ does not affect real output at a 11 . And from equation (1) the change in $\mathrm{m}$ is translated entirely into a point-for-point change in $\mathrm{p}$, apart from any unanticipated shifts in velocity. This famous "policy-ineffectiveness" result, emphasized by Lucas (1973), Sargent and Wallace (1975) and Barro (1976), has understandably stimulated a large volume of research.

The significance of this theory for practical stabilization analysis is not simply the neutrality result -- the idealized general equilibrium model has long been known to yield neutrality as discussed above. Rather the significance is due to the appearance of neutrality in a model which explains the empirically observed correlation between aggregate demand policy and real output. The theory would be of little practical importance if it did not generate this important empirical result. The econometric work of Sargent (1976) and Barro (1977, 1978), has been aimed at making this empirical connection more fomat and rigorous.

I think it is fair to say that this empirical work has demonstrated that the theory is consistent with these correlations. Other facts have been more difficult to reconcile with the theory. The persistence of unemployment is one regularity which does not emerge from 
the simple theory, and was used as a critique of the theory by Hall (1975) and Modigliani (1977). A number of modifications of the theory to account for this persistence have been suggested. Lucas (1975) emphasized that unanticipated shocks could cause firms' capital stock to get out of 1 ine, and this would have repercussions on production in later periods as the capital stock is adjusted, Sargent (1979) emphasized adjustment costs in changing employment. BTinder and Fischer (1978) have placed more emphasis on finished-goods inventory being drawn down or accumulated. Optimal inventory adjustments in later periods will then require production changes and thereby cause a correlation between output changes at different dates. Al1 these theoretical modifications of the basic information-based model with perfectly flexible prices can in principle explain persistence, but it has yet to be demonstrated whether actual inventory behavior or costs of employment adjustment are sufficient to explain the persistence.

There is, of course, much other evidence which the theory can be tested against. Two pieces of evidence which seemingly run counter to the theory are procyclical productivity changes, and a slight tendency for real wages to vary procyclically, though the Tatter is much less pronounced. Sargent (1979), extending the work of Lucas (1970), has shown, however, that these observations are consistent with the limitedinformation flexible price models. His proof involves disaggregating employment into straight-time and over-time, and assuming that straighttime employment is more costly to adjust, but that over-time workers must be paid more on average. Under these conditions firms will find it optimal to employ more straight-time workers than over-time workers on average, but to make larger changes in employment among over-time 
workers than straight-time workers, when demand conditions change across the business cycle. This behavior implies that real average hourly earning will tend to increase during booms, because of the shift of the mix of workers toward higher paid overtime employment, even though real wages may fall for both groups of workers. Moreover, since fewer over-time workers are employed on average than straight-time workers, their marginal productivity is higher. Hence, the shift toward more over-time employment causes average productivity in the economy to increase. Sargent (1978) has attempted to see if this intricate theory is sufficient to explain the phenomena quantitatively, and finds that, although there are some discrepancies, the theory generally conforms to the facts. Another explanation for the procyclical behavior of real wages is given in Phelps (1969) using a model of inventory behavior. New data now becoming available on real inventories may permit a check of this explanation.

From the point of view of stabilization theory a number of extensions of the basic information-based model represented in equation (2) should be mentioned. Cukieman (1979) has shown that the limitedinformation assumptions can be generalized to permit firms to change their expenditures in order to better determine the source of economywide events. This makes the information structure endogenous to the rest of the economy, including policy, and thereby removes the criticism that the theory unrealistically places an exogenous information structure on economic agents. He finds that the general results of the theory are robust with respect to this modification.

McCallum and whitaker (1979) have shown that the policy neutrality result does not apply to such aggregate demand tools as automatic 
stabilizers because these react simultaneously to changes in economic conditions, rather than with a lag as in the feedback monetary policy discussed above. For example, with progressive taxes, after-tax income immediately changes as a fraction of total income when nominal income fluctuates. This can have direct real stabilizing effects. It should be emphasized, however, that in principle monetary policy could be made to operate just as simultaneously as the automatic stabilizers. This has not been the case in practice, however, except for extreme interest rate pegging where the central banks' supply of reserves responds instantaneously to changes in demand.

Uncertainty about Temporary Versus Permanent Changes in Economic Conditions

The theory discussed above emphasizes lack of information about whether demand changes are local or economy-wide. From the viewpoint of stabilization policy, an equally important type of uncertainty is the lack of information about whether an observed economic change is temporary or permanent. Theories which emphasize temporary versus permanent effects are, of course, not new to macroeconomics, as exemplified by Friedman's (1956) original permanent income theory of consumption. Muth $(1960,1961)$ a]so emphasized the distinction in his original work on rational expectations. Here we are concerned with the importance of this uncertainty for the link between aggregate demand and real output. The general point is that a shift in nominal aggregate demand, which is expected to be permanent will have a much smaller effect on real output and a correspondingly larger effect on prices, than a shift which is expected to be temporary. 
Suppose, for example, that in an attempt to reduce the rate of inflation the central bank reduces the growth rate of the money supply. The information problem which economic agents face is whether this change is a permanent one, or whether the central bank will soon give up on its resolve to lower the growth rate of the money supply. In reality, this information problen is not trivial, and cannot be eliminated simply by announcing that today's start at monetary restraint is the beginning of a permanent shift in policy. Lack of credibility about whether the shift is indeed permanent may be cured only by the public observing the results of the new policy.

During the transition period when people learn whether the shift is temporary or permanent, the policy of restraint can have real output effects, even if prices are perfectly flexible. This can be illustrated using the algebra introduced above. 4 Equation (2) can be written in terms of inflation rates rather than price levels by subtracting the lagged price from $p$ and $\hat{p}$. This gives

$$
y_{t}=\alpha\left(\pi_{t}-\hat{\pi}_{t}\right)
$$

when $\hat{\pi}_{t}$ is the expected rate of inflation. Suppose that $\pi_{t}=\hat{\pi}_{t} 50$ that there is initially no uncertainty, but that starting in period $t+1$ the central bank reduces the rate of growth of the money supply to a level that will generate an inflation rate of $\pi_{s}<{ }^{n} t$ for $s>t$. If the new policy is not fully credible, then people will not immediately adjust their expectations to $\pi_{s}$. A reasonable assumption would be that they expect a level of inflation which incorporates the new information

${ }^{4}$ The following discussion is based on Taylor (1975). 
about if as well as the previously expected rate of inflation. In simple terms:

$$
\hat{\pi}_{s}=\lambda \pi_{s}+(1-\lambda) \hat{\pi}_{s-1} \quad s=t+1, t+2, \ldots
$$

Formula (5) can be derived more formally using Bayesian techiques which incorporate the uncertainty about whether the new inflation rate is permanent or whether the observed change is a temporary occurrence. The parameter $\lambda$ will be time dependent in general, however, and this should be taken into account if one is interested in quantitative policy evaluation.

To see the effects of the new monetary policy on real output assume for simplicity that $\pi_{s}$ is equal to a constant $\pi^{*}$ for $s>t+1$. Then from (5) we have

$$
\hat{\pi}_{s}=\lambda \sum_{i=0}^{s-1}(1-\lambda)^{i} \pi^{*}+(1-\lambda)^{5} \pi_{t}
$$

for $s \geq t+1$. Hence, $\hat{\pi}_{s}$ converges to $\pi^{*}$, but will be greater than $\pi^{*}$, if $\pi^{*}$ is less than $\hat{\pi}_{t}$ (if the new monetary policy is to aim for a lower rate of inflation). The gap between the expected rate of inflation $\hat{\pi}_{s}$ and the actual rate of inflation $\pi^{*}$ will be larger, the smaller is $\lambda$. Hence, the less credibility there is about the new policy, the larger the inflation gap and the larger the reduction in real output. There will be no reduction in real output if $\lambda=1$. In this way the uncertainty about permanent versus temporary effects has an important influence on the way policy is linked to real economic variables.

The type of model represented here in very simple terms has been emphasized in stabilization policy analyses by Fellner (1976). 
B. Friedman (1979), and Taylor (1975). A full macroeconomic model developed by Brunner, Cukierman, and Meltzer (1979) uses the distinction between permanent and temporary effects to examine the influence of supply shocks as well as demand shocks on production. Flood and Garber (1979) have provided estimates of similar credibility parameters in the case of monetary reform in the German hyper-inflation.

These types of models have been criticized, especially when used for policy analyses of the type discussed here, because they appear to depend on policy deception (see Barro (1978)). While the potential for deception is clearly present in these models they are equally applicable to situations where all parties disclose their intentions. Unfortunately, disclosure does not generate immediate credibility. It is the problem associated with this lack of credibility which these models emphasize.

\section{Contracts and Relative Price Effects}

Imperfect information is not the only reason that aggregate demand would be expected to influence real output. Temporary rigiditjes in prices or wages might force some of the change in nominal demand into changes in real production. Since casual observation suggests that such rigidities are pervasive either in the form of explicit contracts or less formal implicit contracts, economists have been willing to take these rigidities as given. The main theoretical development in this area during the past several years has been to recognize that the form wich these rigidities takes is important for stabilization analysis. Attempts have been made to model these rigidities with more detail than was previously available, and to trace out 
the implications for policy. Two different forms of this type of analysis can be usefulty distinguished.

The most common form of this type of model assumes that wages are at least temporarily rigid, but that prices are perfectly flexible in the sense that firms cannot directly influence profit margins by marking up their prices relative to wage costs. Firms simply adjust their demand for labor when the real wage shifts against them. Recent examples of this type of model are found in Fischer (1977), Phelps (1978), and Calvo (1980). Letting $w_{t}$ represent the nominal wage and keeping the notation introduced earlier, the most rudimentary form of this model is

$$
y_{t}=a\left(p_{t}-w_{t}\right)
$$

When the real wage rises firms reduce output and employment, until the marginal productivity of labor is increased. If $w_{t}$ is partially predeternined, perhaps because of multiperiod contracts which were set in previous periods, then the 1 ink between aggregate demand and real output follows directly. If aggregate demand is detemined according to equation (1) then

$$
y_{t}=\frac{\alpha}{1+\alpha} m_{t}+\frac{\alpha\left(v_{t}-w_{t}\right)}{1+\alpha}
$$

and clearly changes in nominal $m_{t}$ get translated into real output. The mechanism is simply that a higher money supply raises prices which Towers the real wage and stimulates employment and production.

The major advance in using this type of model has been to develop the mechanism determining the nominal wage. Fischer assumes, for 
:xample, that there are overlapping contracts with a fraction of the contracts set in each period so as to keep the expected real wage zonstant. A consequence of this assumption is that aggregate demand iffects do not persist for longer than the length of the longest consract. Another consequence is that wage or price trends have no :endency to persist. In these two respects this type of model has many Features which are similar to the results of the information-based models. his has led Gramlich (1979), for example, to conclude that wage-rigidities to not add much in the way of policy implications to a rational expecta:ions models. In principle, of course, announced monetary policy affects eal variables in such mode1s, even with rational expectations. This has een emphasized by Fischer (1977). The question is whether they describe :he wage and price dynamics in an empirically accurate way that is relelant for policy analysis.

The main feature of these models is their dependence on real wage shanges for a11 employment effects. As discussed above, it has been Iifficult to find much variation in the real wage over the business ycle. Empirical checks of this model along the lines of Sargent (1978) Ising the distinction between straight-time and over-time workers would sherefore be very useful.

On the other hand, there are important policy problems where hanges in real wages are the central issue. For example, a supply hock could shift the marginal productivity downward requiring a reduc:ion in the real wage. With sticky wages, this reduction might be lifficult without monetary intervention. In effect the monetary luthorities can use monetary policy to shift the price level to a losition such that the real wage is equal to the level which workers 
would have aimed for, if they had known about the shock when they signed the contract. This is the conclusion of Phelps (1978) who bases his anatysis on such a model. Gordon's (1975) analysis of agricultural supply shocks reaches a similar conclusion if farm prices shift up while industrial prices are assumed to be relatively rigid. Blinder (1979) also emphasizes these relative price rigidities in examining the appropriate response of policy to an oil price shock. One difficulty with a]l these analyses is the possibility that the assumed rigid wage (or price) eventually adjusts to offset the policy-induced shift in relative prices. In the Phelps analysis, this is not much of a difficulty in principle because the real wage is pushed toward what workers and firms would have negotiated otherwise. Another difficulty, already alluded to, is that the models do not capture much of the persistence effects of inflation and unemployment which now seem to present important policy problems. In this respect they are similar to the information-based models reviewed above.

Staggered Contracts and Inflation Persistence

By most measures the variability of the general price level in recent years has been larger than the variability of all but a small number of relative prices. For example, the real wage has been relatively stable compared with the sharp rise in nominal wages and prices. Moreover, changes in both nominal wages and prices are more highly correlated with business cycle fluctuation than changes in the relative wage. For these reasons, one might suspect that analyses which focus on real wage changes as the sole cause of employment shifts might be omitting other factors. 
Another class of models which are based on rigidities in wages nd prices deemphasize the aggregate effects of relative price shifts nd focus on the problens of general price movements. These models mphasize the fact that a11 prices and wages are not set in unison cross the economy but are generally staggered, and that a primary eterminant of the price decision is the prevailing price outstanding n the market. Hall (1979) has recently developed a microeconomic odel which gives an explanation for the importance of setting prices elative to the prevailing price.

An example of this type of model is given in Taylor (1979). irms and workers decide on a wage $x_{t}$ in period $t$ which is to last for wo periods. The contract wage $x_{t}$ is set according to the expected revaling wage during the contract pertod with suitable adjustments to eflect demand conditions. Hence

$$
x_{t}=\frac{\hat{w}_{t}+\hat{w}_{t+1}}{2}+\frac{\alpha}{2}\left(\hat{y}_{t}+\hat{y}_{t+1}\right)
$$

here $w_{t}=1 / 2\left(x_{t}+x_{t-1}\right)$ is the average wage at time $t$. The expectaions of $y_{t}$ represent demand pressure on wage decisions. If we make he additional assumption that profit margins are relatively stable hen $p_{t}=w_{t}+\gamma$ where $\gamma$ is a constant parameter which we can set to ero without loss of generality. By holding the relative wage constant, he model purposely abstracts from relative price changes and focuses n general price movements.

In this model, as with the previous model based on price rigidties, aggregate demand policy has a direct effect on real output. If quation (1) is the aggregate-demand relationship, then the mechanism 
works as follows: the price level is predetermined since the wage is predetermined and profit margins do not adjust. Hence, an increase in the money supply increases real balances, which tends to increase the real demand for goods. This results in an increase in production and hence an increase in employment. Eventually wages and prices will adjust because the favorable demand conditions will give firms the incentive to pay increased wage demands. This in turn tends to raise prices and reduce real money balances. Eventually a new equilibrium is reached at a higher price level but with the same level of production. Money is neutral in the long run.

What is different about this model compared with those discussed in the previous section is that convergence to the new equilibrium takes time, and there is never any important shift in relative wages (there is a perfod during which the workers who had settled their contracts when the money supply was changed tend to fall behind other workers but this is not necessarity integral to the workings of the mode1). The inertia in wage movements following the shift in money supply can be demonstrated by solving the model to obtain ${ }^{5}$

$$
x_{t}=\beta x_{t-1} \neq \delta n_{t}
$$

where $\beta$ and $\delta$ depend on the parameter $\alpha$. Hence, a change in the money supply sets off a series of changes in the contract wage $x_{t}$ and hence in the average wage $w_{t}$. This series of changes in $w_{t}$ is matched by the price level $p_{t}$ and, if the money supply is held fixed at the new level,

\footnotetext{
5 The derivation requires the use of rational expectations to solve out for the expectation variables.
} 
is reflected in a similar pattern of changes in real output. Because of these persistence effects this type of model would seem to be more useful for examining stabilization problems associated with reducing inflation, or more generally achieving price stability, than the models discussed in the previous section. If changes in real wages are also thought to be important, then they can easily be incorporated into the analysis. Theoretical frameworks of this kind have been used for policy analysis by Phelps (1978a), Gertler (1977), Modigliani and Papademos (1978), Papademos (1979), and Taylor (1980).

These models have some similarities to the "disequilibrium" models developed by Clower (1965) and Barro and Grossman (1976). Important differences not generally found in "disequitibrium" modes are the use of rational expectations, a reasonably explicit description of the contract mechanism, and a reliance on the more traditional aggregate demand framework without the development of narket spillover effects or of binding supply constraints. These differences largely reflect empirical considerations or modelting strategies. It is not yet clear what is to be gained empirically or theoretically from incorporating disequilibrium spillover effects. A recent paper by Green and Honkapohja (1979) has attempted to bring rational expectations into a framework which corresponds more closely with the disequilibrium models. However, their approach is designed to avoid explicit treatment of the nonlinearities caused by setting market transactions equal to the minimum of supply and demand. Rational expectations are much easjer to deal with in linear models, and this is one reason the "demand is determining" assumption is used. Another reason is that the assumption seems to be empirically realistic in many situations. 
Comparison of the Alternative Theories

What sets the contracting models off from the information-based models is of course the use of "sticky" prices, and the corresponding disuse of the market-clearing assumptions. In the contract madels, markets "clear" in the short run in the sense that supply adjusts to meet the demand; in the long run, prices eventually adjust to clear markets. In the information models, on the other hand, prices instantaneously adjust to clear markets in the short run. Which approach is better? I have used the contracting approach because it corresponds more closely with my interpretation of the market mechanisms in the real world. It is not just the widely discussed long-term labor contracts which suggest this interpretation, but also the much more common (at least in the U.S.) implicit contracts, which are much shorter and are usually not called contracts. In fact, long-term labor contracts have so many indexing provisions that they probably correspond more closely with shorter contracts. Research in this area has shown that "contracts" do not have to be very long to generate a very lengthy persistence of wage and price inflation. (See Taylor (1980), for example.) But in using these contracting models, one has to be aware that without an explicit utility maximization framework, there is a possibility that the models are not robust to changes in policy. Again my preference has been to make the most of these models in situations where the contracting mechanisms are relatively robust.

At the same time, it is difficult not to appreciate the theoretical elegance of the information models, and the potential to use the traditional tools of microeconomics to conduct policy analys is with these mode1s. But even the information-based models have some ad hoc 
assumptions, especially when they need to be modified for empiricat work. One of the major recent developments in the literature on marketclearing rational expectations has been to pursue a more theoretically rigorous approach with the aim of onitting the remaining ad hoc

features, in particular the money demand equation or quantity theory equations (such as equation (1) in this paper). See Wallace (1977) and Cass and Shel1 (1979). 6

The work by Azariadis (1975), Baily (1974), and D.F. Gordon (1976) does not provide as much of a foundation for contract models as one might have originally thought. These theories do not suggest why contracts are set in nominal terms without contingencies. In fact, Barro (1979) has suggested that these microeconomic theories are more useful in showing that the market-clearing models are useful "as if" devices. Calvo and Phelps (1978) and Hall and Lilien (1979) have provided alternative theories of contracts which emphasize the practical and theoretical difficulties of making contracts contingent on everything.

Most of the policy discussions associated with the theories reviewed above have been about the effectiveness of policy or whether policy activism is useful or not. In the market-clearing setting, only

${ }^{6} A$ useful appraisal of the overlapping generations model approach advocated by wallace is contained in Cass and She 11 (1979). The major appeal of this approach is the enormous theoretical mileage one gets from the disaggregation of generations. At an abstract level this disaggregation is very similar to the disaggregation of contracts according to when they are negotiated -- a feature of the contracting models discussed in Section 1.4. More generally one suspects that different types of disaggregation are 7 ikely to yield additional theoretical insights. Another example is the two-sector model explored by Sargent and Wallace (1971), Fenderson and Sargent (1973), and Foley and Sidrauski (1970). 
unanticipated changes in aggregate-demand policy matter, so announced policies do affect output. In contracting nodels aggregate-demand policy has effect whether it is anticipated or not. Hence, in these models, policy is effective and, in certain cases, policy activism is desirable. Some examples of the optimal reaction to supply shocks were discussed above. Mccallum (1977) has argued that price rigidities are not really the source of the policy effectiveness in the contracting models. In criticizing the contract model used by Phelps and Taytor (1977) he shows that monetary policy is ineffective if one removes inventory effects on production, but uses the supply equation in the form of equation (2). However, inventory effects on production are an important part of models where prices do not adjust to clear markets. Firms will want to increase production, for example, if inventories are drawn down below optimal levels because price adjustments are not quick enough. This is the rationale behind the inventory effects on production in the PhelpsTaylor model. Omitting the term attributes suboptimal inventory management to rational firms. This point has been demonstrated by Frydman (1979) in a critique of McCallum's results.

The main outcome of the policy-effectiveness debate is a general consensus that rational expectations per se does not rule out effective aggregate-demand management. It is the flexible-price market-clearing assumption that makes policy ineffective for short run stabilization policy. 7

7 Fischer (1978) and Lucas (1975) mention the nonneutrality that comes even in market-clearing models from the substitution out of money into real capital when the expected rate of inflation rises. However, this mechanism is not seriously considered as a tool of aggregate demand-management. Moreover it is 71 kely to be offset by tax effects. A useful discussion of the relationship between rational expectations and policy effectiveness is found in Lucas (1980). 


\section{POLICIES TO STABILIZE PRICES}

The practical policy implications of these models can be alternatively stated from the viewpoint of price stabilization rather than from the viewpoint of policy intervention to affect output. Suppose, for example, that the rate of inflation is generally agreed to have become too high, either because of past policy mistakes or unavoidable velocity shifts, and that the monetary authorities want to reduce the rate of inflation. The important question is whether the monetary restraint necessary to achieve this goal of price stabilization will cause a recession and how large that recession will be. The answer to that question will obviously influence the policymakers' choice of how much restraint to apply.

If we take Iiterally the information-based models, which emphasize the uncertainty between aggregate and local shocks, then if this policy of restraint is announced it will not have any effect on real output. There will be no recession since inflation will match the reduction in monetary growth point for point. This striking conclusion is, of course, contrary to the views of many economists and policymakers, and I think for this reason the model is still rejected by many economists as a practical guide to policy.

On the other hand, if there is uncertainty about whether the changes in policy are permanent or temporary (as discussed above), then the real effects of policy will exist, and a recession would be expected to occur. The sjze and duration of the recession would depend on the speed with which people begin to believe that the central bank is firm in its resolve to restrain money growth. If the credibility is high or increases quickly, then the recession could be very mild. 
Fellner (1979) indicates why he thinks that credibility is likely to increase quickly, if a clear announced policy of restraint is undertaken, and that people's expectations of inflation would be swiftly revised downwards.

The contract-based models yield different conclusions. The models which emphasize real wage shifts because of asymmetric rigidities do not suggest any reason for a recession to last longer than the length of the average contract. The inflation rate could be put on its new target path in the first period; in the second period wages would adjust. In fact, if the restraining policy was announced and believed one period (year?) in advance, there would be no decline in output. In this case, this type of contract model does not give results that are much different from the market clearing models.

The general staggered contract models suggest, on the other hand, that the recession would be somewhat longer because the adjustment prow cess is passed on gradually from one contract to the next. However, because there are some forward-looking features to these models (see equation (9), the recession would not be expected to be as severe as would be implied by the simple reduced forms (see equation (10)). The policy of restraint (if it is believed) would change the parameters of (10), so as to reduce the size of the recession. Accurate quantitative estimates of how much the parameters would be expected to change have yet to be obtained, though simulation results in Taylor (1980) suggest that it is iikely to be significant.

In sum, each of the models reviewed here has implications about the real effects of a policy of price stabilization. (These models. ignore, of course, any direct positive real effects that a more certain 
Irice level might bring; see Fischer and Modigliani (1979) for a dis:ussion of these direct effects.) In the cases where the real effect s likely to be significant, it would be interesting and useful to compare empirically its magnitude with the estimates provided by conientional econometric techniques as summarized by Okun (1978). This is 1 feasible and well-defined estimation problem as the discussion above lakes clear.

ALTERNATIVE TECHNIQUES FOR THE ANALYSIS OF STABILIZATION POLICY

This section gives an overview of several recent developments soncerning the choice of alternative techniques to analyze stabilization policy. Some of these issues are intimately connected with the theoretical developments summarized in the first section.

The Lucas Critique of Econometric Policymaking

Econometric models have played a large role in policy formulation in recent years. It is rare that the staff members of policymaking agencies do not run alternative policies through the major large scale sconometric models before meeting with their "principals," even if they to not have formal models of their own. Whether this heavy use of aconometric models actually influences the decisions of policymakers is another question. Political or other noneconomic considerations are frequently a factor. But when "pure" economic advice is sought, the results of the econometric models are certainly taken into account. For example, the property of almost all econometric models that nonaccomnodative monetary policy has small effects on prices and large effects on output, undoubtedly influences policymakers to choose more accomnodative policies than they otherwise would. 
Lucas (1976) has criticized this type of econometric policymaking. He argues convincingly that the parameters of these models are not invariant to changes in policy, so that the policy experiments performed on these models (which traat the parameters as fixed) give misleading results. R. J. Gordon (1976) suggests that suitable modifications of econometric policy evaluation procedures could deal with the Lucas criticism. The paraneters could, in principle, be made endogenous.

The parameters of econometric models can shift for many reasons, but the one Lucas emphasized was that rational economic agents would forecast the future effects of policy, and accordingly, modify their behavior in a way not described in the econometric models. To deal with this problem it is necessary at least to reestimate the econometric models taking these expectation effects into account. The most practical way to do this with existing econometric techniques is to use the rational expectations assumption. Having specified and estimated an econometric model with rational expectations it is then possible to perform a policy analysis to take account of the expectations effects. This is the approach taken by Taylor (1979a). A simple quarterly econometric model of the U. S. economy was estimated during the 19541976 period, imposing rational expectations on economic agents. Using the estimated parameters of this model, alternative policies were compared, and for a given set of policy preferences, optimal policies were calculated. Because the model incorporated contracts of the kind discussed above, a policy tradeoff between inflation and unemployment was implied by the model and this was calculated using the estimated parameters. The tradeoff was characterized by a "best" relationship 
setween output stability and price stability. ${ }^{8}$ This optimal relationship apparently dominated actuat policy during the period as well as the policy of a constant growth rate for the money suppiy. Constant noney growth would have given better results than actual policy, howsver, according to these estimates.

Anderson (1979) and Fair (1979) have tried to estimate the quantitative significance of the Lucas critique by simulating convention$117 y$ estimated econometric models, with rational expectations inserted. They both find the effects to be quantitatively significant, but their results are difficult to interpret because the conventional models were lot formulated as rational expectations models. For example, Anderson (1979) finds that the Phillips curve is much steeper when he imposes ational expectations on the mode]. But clearly the specifiers of his nodel would have altered its specifications if they knew rational exjectations would be imposed. It is Tikely that the adaptive expectations distributed lags used in such models are designed to capture ther dynamic properties than pure extrapolative forecasting.

Quantitative work of this kind with rational expectations is only just beginning. More experience with these techniques will be lecessary before they can be accurately appraised as sianificant imsrovements over conventional econometric policy evaluation procedures. The results available thus far are promising, are already giving rough

${ }^{8}$ Flemming (1976) p. 73 suggests that a tradeoff between output stability and price stability might be a good way to characterize the jolicy problem. Phelps and Taylor (1977), Taylor (1980), and Green and tonkapohja (1979) have calculated theoretical tradeoffs of this kind. in international comparison of such tradeoffs is given in Taylor ?'1980a). 
empirical estimates of the effect of policy, and indicate that further research is fruitful.

Two objections can be raised against these attempts to account for the Lucas critique. One is that the rational expectations assumption is not accurate because it does not incorporate learning on the part of individuals about the economy. If this learning problem is significant, then these techniques will have to be modified. Learning effects are likely to be a serious empirical problem immediately following a major economic reform. This was illustrated above for the case where the monetary authorities change their policy and people do not know whether it is a permanent or temporary change. However, even if learning problems are significant, these techniques will be useful for evaluating alternative policy procedures over a long period of time. For example, it is useful to know if a less accommodative monetary policy during the 1960s and 1970s would have increased the amplitude of business cycle fluctuations as much as conventional econometric models would imply. If the use of rational expectations gave results much different from other models over long enough periods for the rational expectations assumption to be realistic, then the results would be taken into consideration in recommending how accomodative policy shoutd be in the 1980s.

Another objection to the quantitative use of rational expectam tions as described here is that there are other reasons that parameters of a model could change. For example, even if rationat expectations were used, behavioral relations for contract-wage detemination might shift with policy as workers and firms change contract lengths. While expectations are probably a significant source of parameter drift, this 
does not mean that models can ignore other behavioral shifts. Successful policy evaluation requires careful modelling of all behavioral relations.

The New Equilibrium Approach to Policy Evaluation

Lucas and Sargent (1978) have suggested that the pervasiveness of these other sources of parameter shifts means that minor modifications of econometric models are not sufficient. They recommend a "new equilibrium" approach to modelling in which all economic relations are based on explicit utility maximization analysis. If tastes and technology remain relatively constant ... or can be model led as exogenous factors -- then this approach, in principle, will avoid these other types of parameter shifts. The approach is attractive because once one has developed a model based on sound utility maximization principles, macroeconomic policy analysis is conducted like any other welfare analysis in microeconomics. Explicit externalities can be located and offset by optimal policies, and no approximate aggregate welfare criteria such as output and price stability are necessary. One would design policy to maximize the welfare of the representative individua?. Attempts to design business cycle or econometric models along these lines include the work by Barro (1976), Lucas (1975), Hansen and Sargent (1980) and kydland and Prescott (1980).

This approach represents a fundamental change in macroeconomic policy evaluation and its full practical implementation will take a long time as emphasized by Lucas and Sargent (1978). As an alternative to the approach outlined in the previous section, several reservations about this new equilibrium approach might be mentioned. Does utility 
maximization provide any additional constraints on an economic model which do not already come from a set of explicit decision rutes and rational expectations? If it does not, then the gains from beginning each analysis with explicit utility maximization are not clear. For example, one of the major ad hoc features of decision rules designed for empirical work is that they include lags to capture the gradual adjustment of firms to new economic conditions. With uti]ity maximization, these lags are "explained" by adjustment costs which tend to make it optimal for firms to adjust slowly. But one has almost as much freedom to choose adjustment costs in a utility framework as one does to choose lag length when writing down decision rules. Unless good microeconomic or technological information is available to measure these adjustment costs, the utility maximization approach does not seem to provide additional information in this case.

Another reservation concerns the practical use of the welfare of the representative individual as the criterion for stabilization policy. In principle this approach is better than the alternative approach of postulating an aggregate measure of welfare, which might include measures of inflation or aggregate employment stability. But the aggregate welfare approach has advantages in practice. It is very difficult to incorporate some of the welfare gains of price stability into individual utility functions. The gains from a relatively stable aggregate price level involve such considerations as providing a more certain framework for private decision making. Until one finds a way to incorporate these complex effects into individual utility functions, the use 
of aggregate criteria may serve as satisfactory and workable

al ternatives.

\section{Rules Versus Discretion}

The debate between those favoring rules versus discretion has not diminished in recent years but the arguments have been modified. A definitional change is that rules are now rarely taken to mean holding policy instruments constant. Feedback rules, in which the money supply responds in a systematic way to economic developments, are rules as much as constant money growth.

Kydland and Prescott (1977) have suggested that the problem of time inconsistency (see also calvo (1979)), implies that rules should be used rather than discretion. Time inconsistency can arise because of taste change or because people forecast future behavior of policymakers. In both cases policymakers may be tempted to change plans after they have announced the optimal path. Time inconsistency does not imply that optimization techniques cannot be used (see Fischer (1980) for a discussion of this issue), but it does raise questions of how policy should be implemented. Kydland and Prescott (1977) argued that rules would be a way to reduce the incentive for policymakers to change plans. Rules do not generaliy exploit the initial conditions of a maximization problem as much as fully optimal policies. If policymakers do not exploit initial conditions today, then people might expect that they will not exploit initial conditions in the future. But of course there is no logical guarantee. This 
preference for rules over discretion is a practical, rather than a logical, implication of time inconsistency problems. 9

Another practical reason to prefer rules over discretion is that, especially with rational expectations, it is difficult to estimate the impact of alternative discretionary paths with great accuracy. The rational-expectations assumption is not accurate unless one can assume people are familiar with how policy works; this might require that they have experience with one type of rule for a long period of time. 10

Fischer (1979) has suggested a compromise resolution to the rules versus discretion debate: rules should be used in normal times, but in the case of an unanticipated disaster (such as a financial panic) dism cretion should come into play. It is difficult to disagree with this eclectic solution to the problem, but practical implementation might prove difficult. Objective measures of what is normal and what is abnormal are difficult to obtain in economics.

A less constructive, but perhaps more realistic resolution to the rules versus discretion debate comes from deemphasizing the distinction between the two. If policymakers make the same policy decision whenever their staffs: econometric forecasts are the same, then in effect

9 Monetarists who advocate the use of a fixed money growth rule, suggest that, because of initial conditions (a high inflation rate inherited from the past), the growth rate be diminished to the target path slowly when starting out on such a plan. There is a time inconsistency argument here. If higher rates of money growth are advocated because of initial condition, then what is to keep people from expecting a return to high money growth when similar conditions arise again in the future?

10 Another practical reason is that statistical estimates of policy effects are considerably less complex if one can focus on rules. 
they are using rules. The rules might be difficult to describe and even more difficult to estimate, but they are rules nonetheless. If this is a good description of the way policy works, then research which focuses on alternative rules rather than discretionary paths might turn out to be the more practically useful type of policy research. Such research might suggest ways in which the policymaking process (rule) should be modified in order to improve the performance of the economic system.

\section{CONCLUDING REMARKS}

This overview has been aimed at recent theoretical research in stabilization theary. Earlier research on such issues as the choice of intermediate targets, problems of lags in the effect of policy, and the effect of parameter uncertainty on the choice of policy instrument has been omitted largely because theoretical developments in these areas have been relatively minor in recent years. It should be emphasized that these older problems continue to be of practical importance. The continuing efforts to persuade the fed to switch to a reserve targeting procedure in their short-run operating strategy is a case in point.

The practical interpretation of these earlier stabilization issues has been changed in some cases, however, by the theoretical developments reviewed in this paper. For example, Poole's (1970) analysis of the choice of policy instrument loses most of its practical relevance in the mark-t-clearing models where monetary policy is ineffective. But $i_{i 1}$ the contracting models, where monetary policy effects on real output are significant, Poole's analysis needs only slight modifications to account for the rational expectations effects. Interest rate 
pegging frequently leads to instability in rational expectations models, whether prices are flexible or temporarity rigid. This policy implication, which was emphasized by Sargent and Wallace (1975), appears to be robust to change in the theory which is used. 11 That many other important policy implications are not robust to changes in alternative theories -- as was emphasized here for the policy objective of price stabilization -- suggests that additional theoretical and empirical work to sort out and test these theories should be high on any agenda for future research on stabilization policy.

${ }^{11}$ Such instability can occur in the model used by Phelps and Taylor (1977) for example. Because prices are set at levels which clear markets on average, market-clearing conditions are used to determine expected future prices which in turn are used to determine the current price setting. Extreme interest rate pegging can make future prices and hence the current price level undetermined.

$-34-$ 


\section{REFERENCES}

Anderson, P. A. (1979) "Rational Expectations Forecasts for NonRational Models, Journal of Monetary Economics, 5, 67-80.

Azariadis, C. (1975) "Implicit Contracts and Underemployment Equilibrium," Journal of Political Economy, 83, $1183-1202$.

Baily, M. N. (1974) "Wages and Employment under Uncertain Demand," Review of Economic Studies, 41, 37-50.

Bal1, R. J, et al. (1978) Report of the Committee on Policy Optimization, Her Majesty's Stationery office, London.

Barro, R. J. (1976) "Rational Expectations and the Role of Monetary Policy," Journal of Monetary Economics, 2, 1-32.

(1977) "Unanticipated Money Growth and Unemployment in the United States," American Economic Review, 67, 101-15.

(1978) "Unanticipated Money, Output and the Price level in the United States," Journal of Pojitical Economy, 86, 549-80.

(1979) "Developments in the Equilibrium Approach to Business Cycles," unpublished, University of Rochester.

Barro, R. J. and H. J. Grossman (1976) Money, Employment and Inflation, Cambridge, Cambridge University press.

Blinder, A. (1979) "Supply-Shock Inflation: Money Expectations, and Accomodation," M. J. Flanders and A. Razin (Eds.), Development in an Inflationary Wor]d, Academic Press, Forthcoming.

Blinder, A. and S. Fischer (1978) "Inventories, Rational Expectations and the Business Cycie," unpublished.

Brunner, K., A. Cukierman, and A. Meltzer (1979) "Stagfiation, Macroeconomics and the Permanence of Economic Shocks," CarnegieMellon Working Paper, February.

Buiter, W. (1979) "The Macroeconomics of Dr. Pangloss, A Critical Survey of the New Classical Macroeconomics, unpublished, princeton University.

Calvo, G. (1979), "On the Time Consistency of Optimal Policy in a Monetary Economy," Econometrica, 46, 1471-7428.

(1980), "Tax Financed Government Spending in a Neoclassical Model with Sticky Wages and Rational Expections," Journal of Economic Dynamics and Control, 2, Forthcoming. 
Calvo, G. and Phelps, E. S. (1978), "Enployment and Contingent Wage Contracts," in Stabilization of the Domestic and International Economy, K. Brunner and A. Meltzer (Eds.), North-Holland, Ams terdan.

Cas5, D. and K. Shell (1979), "In Defense of a Basic Approach," California Institute of Technology, Social Sciences Working Paper No. 282.

Clower, R. (1965), "The Keynesian Counterrevolution: A Theoretical Appraisal," in Theory of Interest Rates, Conference on the Theory of Interest and Money, F. H. Hahn and F. P. Brechling, (eds.), London, Macmillan.

Cukierman, A. (1979) "Rational Expectations and the Role of Monetary Policy: a Generalization," Journal of Monetary Economics, 5 , 213-30.

Fair, R. C. (1979), "An Analysis of a Macroeconomic Model with Rational Expectations in the Stock and Bond Markets," American Economic Review, 67, 539-552.

Feldstein, M. (1978) "The Private and Social Costs of Unemployment," American Economic Review Papers and Proceedings, 68, 155-158.

Fellner, W. (1976) Towards a Reconstruction of Macroeconomics: Problems of Theory and Policy, American Enterprise Institute, Washington.

(1979) "The Credibility Effect and Rational Expectations," Brookings Papers on Economic Activity, 1, 167-178.

Fischer, 5. (1977) "Long Term Contracts, Rational Expectations, and the optinal Policy Rule" Joumal of Political Economy, 85, 191-206.

- (1979) "On Activist Monetary Policy with Rational Expectations," in S. Fischer (ed.) Rational Expectations and Economic Policy, University of Chicago Press, Chicago (forthcoming).

- (1980) "Dynamic Inconsistency, Co-operation, and the Benevolent Dissembing Government," Journal of Economic Dynamics and Control, 2, forthcoming.

Fischer, S. and F. Modigliani (1978) "Towards an Understanding of the Real Effects and Costs of Inflation," Weltwirtschaftliches Archiv, 114, 810-833.

Fleming, J. (1976), Inflation, Oxford University Press.

Flood, R. P. and P. M. Garber (1979) "An Econonic Theory of Monetary Reform," Journa of Political Economy, forthcoming. 
Foley, D. K, and M. Sidrauski (1970), "Portfolio Choice, Investment and Growth," American Economic Review, 70, (March) 44-63.

Friedman, B. (1979) "Optimal Expectations and the Extreme Information Assumptions of 'Rational Expectations' Macromodels, " Journal of Monetary Economics, 5, 23-42.

Friedman, M. (1956) A Theary of the Consumption Function, New York, National Bureau of Economic Research.

.(1968) "The Role of Monetary Policy," American Economic Review, 58, 1-17.

Frydman, R. (1979) "Sluggish Price Adjustments and the Effectiveness of Monetary Policy under Rational Expectations," unpublished paper, New York University.

Gertler, M. (1977) "Rational Inflationary Expectations and the Disequilibrium Versus Equilibrium Methods in Macroeconomics," Stanford Workshop on Inflation, Discussion Paper No. 15.

Gordon, D. F. (1976) "A Neo-Classical Theory of Keynesian Unemployment," in K. Brunner and A. H. Meltzer (Eds.) The Phillips Curves and Labor Market, North-Holland, Amsterdam.

Gordon, R. J. (1975) "Alternative Responses of Policy to External Supply Shock," Brookings Papers on Economic Activity, 183-204.

.(1976) "Can Econometric Policy Evaluation be Salvaged?: A Comment" in The Phillips Curve and Labor Markets, eds. K. Brunner and A. H. MeTtzer, North-Fol1and, Amsterdam.

Gramlich, E. M. (1979) "Macro Policy Responses to Price Shocks," Brookings Papers on Economic Activity, 125-167.

Green, J. and S. Honkapohja (1979), "Variance Minimizing Monetary Policies with Lagged Price Adjustment and Rational Expectations," Harvard Institute of Economic Research, Discussion Paper Number 721.

Ha1l, R. E. (1975) "The Rigidity of Wages and the Persistence of Unemployment," Brookings Papers on Economic Activity, 2, 307-35.

(1979) "The Role of Prevaiting Prices and Wages in the Efficient Organization of Markets," unpublished paper, Stanford University.

Ha11, R. and D. Lilien (1980) "Efficient Wage Bargains under Uncertain Supply and Demand," American Economic Review, forthcoming.

Hansen, L. P. and T. J. Sargent (1980) "Formulating and Estimating Dynamic Linear Rational Expectations Models, "Journal of Economic Dynanics and Control, 2, forthcoming. 
Henderson, D. W. and T. J. Sargent (1973), "Monetary and Fiscal Policy in a Two-Sector Aggregative Mode1," American Economic Review, 63, $345-365$.

Kydland, F. and E. C. Prescott (1977), "Rules Rather than Discretion: The Inconsistency of Optimal Plans," Journal of Political Economy, $85,473-492$.

\section{(1980), "Dynamic Optimal Taxation,} Rational Expectations, and Control Theory," Journal of Economic Dynamics and Control, 2, 1, forthcoming.

Lucas, R. E. (1970) "Capacity, Overtime, and Empirical Production Functions," American Economic Review Paper and Proceedings, 60, 23-27.

(1973) "Some International Evidence on Output-Inflation Tradeoffs," American Economic Review, 63, 326-34.

. (1975) "An Equilibrium Model of the Business Cycle," Journal of Political Economy, 83, 1113-44.

(1976) "Econometric Policy Evaluation: a Critique," Journal of Monetary Economics, Supplement, 19-46.

(1980) "Rules, Discretion, and the Role of the Economic Advisor" in S. Fischer (Ed.), Rational Expectations and Economic Policy, forthcoming.

Lucas, R. E. and T. J. Sargent (1978) "After Keynesian Macroeconomics," Federal Reserve Bank of Boston, After the Phillips Curve: Persistence of High Inflation and High Unemp Toyment.

McCallum, B. T. (1977) "Price-Level Stickiness and the Feasibility of Monetary Stabilization Policy with Rational Expectations," Journal of Political Economy, 85, 627-34.

. (1979) "The Current State of the Policy-Ineffectiveness Debate," American Economic Review, Papers and Proceedings, 69, $240-245$.

McCallum, B. T. and J. K. Whitaker (1979) "The Effectiveness of Fiscal Feedback Rules and Automatic Stabilizers under Rational Expectations," Journal of Monetary Economics, 5, 171-86.

Modigliani, F. (1977) "The Monetarist Controversy or, Should We Forsake Stabilization Policies?", American Economic Review, 67, 1-19.

Modigliani, F. and L. Papademos (1978) "Optimal Demand Policies Against Stagflation," Wel twirtschaftliches Archiv, 114, 736-781. 
Muth, J. F. (1960) "Optimal Properties of Exponentially Weighted Forecasts, Journal of the American Statistical Association, 55, $299-306$.

(1961) "Rational Expectations and the Theory of Price Movements," Econometrica 29, 315-335.

Okun, A. (1978) "Efficient Disinflationary Policies," American Economic Review, Papers and Proceedings, 68, 348-352.

Papademos, L. (1979) "Stagflation and Monetary Policy," unpublished paper, Columbia University.

Phelps, E. S. (1969) "Short-Run Employment and Real Wage in Competitive Markets," International Economic Review, 10, 220-232.

et al (1970) Microeconomic Foundation of Employnent and Inflation Theory, Norton, New York.

- (1978) "Commodity Supply Shocks and Ful1-Employment Monetary Policy," Journal of Money, Credit and Banking, 10, 2, 206-221.

-(1978a) "Disinflation without Recession: Adaptive Guideposts and Monetary Policy," Weltwirtshaftliches Archiv 114.

. (1979) "Introduction: Developments in Non-Wal rasian Theory" in E. S. Phe1ps Studies in Macroeconomic Theory, Academic Press, New York.

Phelps, E. S. and J. B. Taylor (1977) "Stabilizing Powers of Monetary Policy under Rational Expectations," Journal of Political Economy, 85. $163-190$.

Poole, W. (1970) "Optimal Choice of Monetary Policy Instruments in a Simple Stochastic Macromodel," Quarterly Journal of Economics, 197-216.

Prescott, E. S. (1977) "Should Control Theory Be Used for Economic Stabilization," in K. Brunner and A. H. Meltzer (Eds.) Optimal Policies, Control Theory and Technology Exports, North-Holland, Ams terdam.

Santomero, A. M. and J. J. Seater (1978) "The Inflation-Unemployment Trade-0ff: A Critique of the Literature," Journal of Economic Literature, 16, 499-544.

Sargent, T. 3. (1976) "A Classical Macroeconometric Model for the United States," Journal of Political Economy, 84, 207-238.

- (1977) "The Persistence of Aggregate Employment and the Neutrality of Money," unpubiished. 
Sargent, T. J. (1978), "Estimation of Dynamic Labor Denand Schedules under Rational Expectations, Journal of Political Economy, $86,1009-1044$. (1979) Macroeconomic Theory, Academic Press, New York.

Sargent, T. J. and N. Wallace (1971) "Market Transactions, Costs, Asset Demand Functions, and the Relative Potency of Monetary and Fiscal Policy," Journal of Money, Credit and Banking, 3, 469-505. (1975) "Rational Expectations' the OptimaT Monetary Instrument and the Optimal Money Supply RuTe," Journal of Political Economy Apri1 241-254.

Shiller, R. (1978) "Rational Expectations and the Dynamic Structure of Macroeconomic Models: A Critical Review, Journal of Monetary Economics, 4, 1 (January), 1-44.

Taylor, J. B. (1975) "Monetary Policy during a Transition to Rational Expectations, Journal of Political Economy 83, 1009-1021.

- (1979) "Staggered Wage Setting in a Macro Mode1," American Economic Review, Papers and Proceedings, $108-113$.

(1979a) "Estimation and Control of a Macroeconomic Model with Rational Expectations," Econometrica, September, forthcoming.

(1980) "Aggregate Dynamics and Staggered Contracts," Journal of Political Econony, forthcoming.

(1980a) "Output and Price Stabi]ity: An Internationai Comparison," Journal of Economic Dynamics and Control, 2, February, forthcoming.

Wa1lace, N. (1977) "Why the Fed Should Consider Holding Mo ronstant," Federa] Reserve Bank of Minneapol is Quarterly Review, Summer Issue, $2-10$. 